\title{
ANALYSIS ON THE MODIFIED LYSHOLM FUNCTIONAL PROTOCOL AMONG PATIENTS WITH NORMAL KNEES
}

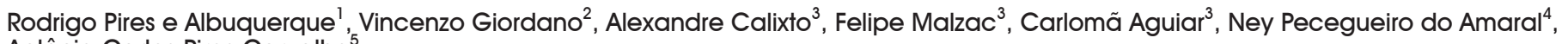
Antônio Carlos Pires Carvalho ${ }^{5}$

\section{ABSTRACT}

Objective: To evaluate the modified Lysholm protocol among patients with knees that were considered to be normal (without previous complaints or pathological conditions in this region). Method: Between January 2010 and March 2010, a prospective study was conducted on 300 patients with orthopedic complaints in other regions of the body who came to the emergency service of our hospital. The inclusion criterion among these patients was the absence of complaints or previous surgery in the knee that was considered to be dominant. The age range was from 16 to 40 years, with an average of 28.8 years. Our study group consisted of 153 males and 147 females. In the modified Lysholm system, the maximum score is 100 points and this includes functional and objective criteria. Altogether, $50 \%$ of the total score is based on symptoms of pain and instability. Results: The average score using the Lysholm protocol was 95 points in the knees that were considered normal. Males had higher scores than females. Conclusion: These patients with knees that were considered normal did not achieve the maximum score when evaluated using the modified Lysholm protocol. This study suggests that this line of research on functional evaluation systems for the knee is open for further evaluations. Moreover, creation and development of new forms of functional assessment for the knee should be investigated in order to achieve a worldwide consensus.

Keywords - Knee; Follow-Up Studies; Evaluation

\section{INTRODUCTION}

Numerous systems have been developed recently to evaluate the pre- and postoperative condition of patients who are submitted to surgical procedures in the knee region. The protocol format can vary, but is usually based on functional and clinical evaluations. O’Donoghue was the first to apply a metric scale system for the evaluation of postoperative results ${ }^{(1)}$.

The concern about documenting results and being able to compare them validly with those obtained by other colleagues appears to us to be the major motivation for the use of formal evaluation systems.

Thus, we observed a wide variety of possible methods of evaluation of surgical procedures at the level of the knee in the literature investigated. Among which we proposed an evaluation of the modified Lysholm score ${ }^{(2)}$ (Attachment 1). The choice of this scoring system was based on the modified Lysholm protocol as it is one of the protocols used most often in literature, and, until the start of the survey, the only one validated in Brazil ${ }^{(3)}$. The authors' goal was

1 - Master's and Doctor's degree in Medicine; Orthopedist and Coordinator of the Knee Surgery Division of the Serviço de Ortopedia e Traumatologia Professor Nova Monteiro - Hospital Municipal Miguel Couto (SOT-HMMC) - Rio de Janeiro, RJ, Brazil.

2 - Master's degree in Medicine; Orthopedist and Coordinator of the Medical Residency Program of the Serviço de Ortopedia e Traumatologia Professor Nova Monteiro Hospital Municipal Miguel Couto (SOT-HMMC) - Rio de Janeiro, RJ, Brazil.

3 - Master's degree in Medicine; Orthopedist, Collaborator of the Serviço de Ortopedia e Traumatologia Professor Nova Monteiro - Hospital Municipal Miguel Couto (SOT-HMMC) - Rio de Janeiro, RJ, Brazil.

4 - Head of the Serviço de Ortopedia e Traumatologia Professor Nova Monteiro - Hospital Municipal Miguel Couto (SOT-HMMC) - Rio de Janeiro, RJ, Brazil.

5 - Master's degree and Doctor's degree in Medicine; Associate Professor of the Department of Radiology of Universidade Federal do Rio de Janeiro - Rio de Janeiro, RJ, Brazil.

Study conducted at the Serviço de Ortopedia e Traumatologia Professor Nova Monteiro - Hospital Municipal Miguel Couto (SOT-HMMC) - Rio de Janeiro, RJ, Brazil.

Mailing address: Av. Henrique Dodsworth, 83, ap. 105, Copacabana - 22061-030 - Rio de Janeiro, RJ, Brazil. Email: rodalbuquerque@ibest.com.br

Study received for publication: 12/29/2010, accepted for publication: 3/25/2011.

The authors declare that there was no conflict of interest in conducting this work 
to evaluate the modified Lysholm scoring system in patients with knees considered normal, i.e., without complaints or previous pathologies in this region.

\section{METHOD}

To apply the modified Lysholm scoring system, we prospectively evaluated 300 patients who appeared at the emergency department of our hospital with orthopedic complaints in other body regions. Of these, 153 were men and 147 women with a mean age of 28.8 years ( 16 to 40 years), involving 248 right knees and 52 left knees. The age criterion was imposed as we know that patients over 40 years of age present a greater risk of knee osteoarthritis, which could mask our functional evaluation. The criterion of inclusion of the patients was absence of complaints or previous surgery on the knee considered dominant. The group was evaluated by a single physician, member of the Brazilian Society of Knee Surgery and with a postgraduate degree (master's), performing bilateral radiographic exam and exhaustive clinical examination, searching for meniscal, ligament and patellofemoral pathologies.

In the modified Lysholm system the maximum score is 100 points, in which: 91 to 100 points is considered excellent; 84 to 90, good; 65 to 83, fair; and 64 or less, unsatisfactory. Lysholm's system is an evaluation system that includes three functional criteria and five subjective criteria. All told, $50 \%$ of the total score is based on the symptoms of pain and instability ${ }^{(2)}$. The descriptive analysis presented the

Attachment 1 - Modified Lysholm.

\begin{tabular}{|c|c|}
\hline $\begin{array}{l}\text { Modified Lysholm limp } \\
\text { (5 points) }\end{array}$ & $\begin{array}{l}\text { None }=5 \\
\text { Slightly or periodically }=3 \\
\text { Severe or constant }=0\end{array}$ \\
\hline Support (5 points) & $\begin{array}{l}\text { None }=5 \\
\text { Limp }=2 \\
\text { Weight-bearing impossible }=0\end{array}$ \\
\hline Locking (15 points) & $\begin{array}{l}\text { No locking or crepitation sensation }=15 \\
\text { "Catching" sensation but no locking sensation = } 10 \\
\text { Occasional locking }=6 \\
\text { Frequently }=2 \\
\text { Locked joint on examination }=0\end{array}$ \\
\hline Instability (25 points) & $\begin{array}{l}\text { Has never presented buckling }=25 \\
\text { Rarely during sports activities or other exertion }=20 \\
\text { Frequently during sports activities or other exertion }=15 \\
\text { Occasionally in daily living activities }=10 \\
\text { Frequently in daily living activities }=5 \\
\text { With every step }=0\end{array}$ \\
\hline Pain (25 points) & $\begin{array}{l}\text { None }=25 \\
\text { Inconstant and slight during severe exertion }=20 \\
\text { Marked during severe exertion }=15 \\
\text { Marked on or after walking } 2 \mathrm{~km} \text { or more }=10 \\
\text { Marked on or after walking less than } 2 \mathrm{~km}=5 \\
\text { Constant }=0\end{array}$ \\
\hline Joint effusion/swelling (10 points) & $\begin{array}{l}\text { None }=10 \\
\text { On severe exertion }=6 \\
\text { On slight exertion }=2 \\
\text { Constant }=0\end{array}$ \\
\hline Stair climbing (10 points) & $\begin{array}{l}\text { No problem }=10 \\
\text { Slightly impaired }=6 \\
\text { Step by step (one stair at a time) }=2 \\
\text { Impossible }=0\end{array}$ \\
\hline Squatting (5 points) & $\begin{array}{l}\text { No problem }=5 \\
\text { Slightly impaired }=4 \\
\text { Up to } 90 \text { degrees }=2 \\
\text { Impossible }=0\end{array}$ \\
\hline TOTAL COUNT & \\
\hline \multicolumn{2}{|c|}{ Result (first letter) } \\
\hline Excellent: $91-100$ & Poor: $<$ or $=64$ \\
\hline
\end{tabular}

Source: Tegner Y, Lysholm J. Rating systems in the evaluation of the knee ligament injuries. Clin Orthop 1985;198:43-9. 
observed data in table form, expressed in the form of frequency (n) and percentage (\%) for the individual aspects and general classification of the modified Lysholm system, and of mean \pm standard deviation and median for age (in years) and total score (in points), together with illustrative graphs.

Aiming to verify whether there is a significant difference in the individual aspects, general classification and total score of the modified Lysholm system between sexes, we considered the following tests: $\chi^{2}$ or Fisher's exact test for categorical factors and the Student's t-test for independent samples or the Mann-Whitney test (total score) for numerical variables. The homogeneity of variance was verified by Levene's test.

The significance determination criterion adopted was the level of $5 \%$. The statistical analysis was processed by the statistical software SAS ${ }^{\circledR}$ System, version 6.11.

\section{RESULTS}

Tables 1 and 2 provide the frequency (n) and the percentage $(\%)$ of the clinical characteristics and of the individual aspects and the general classification of the modified Lysholm score, respectively.

The age and the total modified Lysholm score (in points) were expressed through mean \pm standard deviation and median.

The analysis observed that $26 \%$ of the individuals exhibited some type of impairment, i.e., did not reach the maximum score, whereas $9.3 \%$ obtained a fair or poor result (Figure 1).

The survey verified that $42.7 \%$ of the individuals exhibited some type of symptom related to the lock-

Table 1 - Description of the characteristics of the general sample.

\begin{tabular}{c|c|c|c}
\hline \multirow{2}{*}{ Variable } & Category & $\mathrm{n}$ & $\%$ \\
\hline \multirow{2}{*}{ Sex } & Male & 153 & 51.0 \\
\cline { 2 - 4 } & Female & 147 & 49.0 \\
\hline \multirow{2}{*}{ Knee (side) } & Right & 248 & 82.7 \\
\cline { 2 - 4 } & Left & 52 & 17.3 \\
\hline Age (years) & \multicolumn{3}{|c}{$29.3 \pm 6.1-29$} \\
\hline
\end{tabular}

* Expressed in mean $\pm \mathrm{SD}-$ median.

Source: SOT-HMMC, 2010.
Table 2 - Distribution of aspects and general classification of the modified Lysholm system.

\begin{tabular}{|c|c|c|c|}
\hline Modified Lysholm & Category & $\mathrm{n}$ & $\%$ \\
\hline \multirow{3}{*}{ Limp } & Severe or constant & 1 & 0.3 \\
\hline & Slightly & 7 & 2.3 \\
\hline & None & 292 & 97.4 \\
\hline \multirow{2}{*}{ Support } & Limp & 14 & 4.7 \\
\hline & None & 286 & 95.3 \\
\hline \multirow{4}{*}{ Squatting } & Impossible & 1 & 0.3 \\
\hline & Up to 90 degrees & 1 & 0.3 \\
\hline & Slightly impaired & 24 & 8.0 \\
\hline & No problem & 274 & 91.4 \\
\hline \multirow{2}{*}{ Stair climbing } & Slightly impaired & 39 & 13.0 \\
\hline & No problem & 261 & 87.0 \\
\hline \multirow{2}{*}{$\begin{array}{l}\text { Joint effusion/ } \\
\text { swelling }\end{array}$} & On severe exertion & 39 & 13.0 \\
\hline & None & 261 & 87.0 \\
\hline \multirow{3}{*}{ Locking } & Occasional & 8 & 2.7 \\
\hline & "Catching" sensation & 120 & 40.0 \\
\hline & None & 172 & 57.3 \\
\hline \multirow{4}{*}{ Pain } & $\begin{array}{c}\text { On walking } 2 \mathrm{~km} \text { or } \\
\text { more }\end{array}$ & 8 & 2.7 \\
\hline & On severe exertion & 26 & 8.7 \\
\hline & Inconstant or slight & 88 & 29.3 \\
\hline & None & 178 & 59.3 \\
\hline \multirow{3}{*}{ Instability } & $\begin{array}{l}\text { Occasionally in daily } \\
\text { activities }\end{array}$ & 5 & 1.7 \\
\hline & $\begin{array}{l}\text { Rarely during sports } \\
\text { activities }\end{array}$ & 16 & 5.3 \\
\hline & $\begin{array}{c}\text { Has never presented } \\
\text { buckling }\end{array}$ & 279 & 93.0 \\
\hline \multirow{4}{*}{$\begin{array}{c}\text { General } \\
\text { classification }\end{array}$} & Excellent & 222 & 74.0 \\
\hline & Good & 50 & 16.7 \\
\hline & Fair & 27 & 9.0 \\
\hline & Poor & 1 & 0.3 \\
\hline \multirow{2}{*}{$\begin{array}{c}\text { General } \\
\text { classification } \\
\text { (grouped) }\end{array}$} & Excellent & 222 & 74.0 \\
\hline & Not excellent & 78 & 26.0 \\
\hline $\begin{array}{l}\text { Total score } \\
\text { (points)* }^{\star}\end{array}$ & \multicolumn{3}{|c|}{$93.2 \pm 6.9-95$} \\
\hline
\end{tabular}

* Expressed in mean $\pm \mathrm{SD}-$ med ian.

ing aspect; followed by the pain aspect, with $40.7 \%$; and climbing stairs, with $13 \%$. The analysis suggests that, although the individuals do not have a diagnosed prior or current pathology, they already present some symptomatology, not obtaining the maximum concept of the score (Figure 2). 
Table 3 provides the frequency (n) and the percentage $(\%)$ of the individual aspects and the general classification of the modified Lysholm according to sex (male and female) and the corresponding descriptive level ( $p$ value) of the statistical test.

The statistical analysis was composed of the $\chi^{2}$ or Fisher's exact tests for the individual aspects and general classification and by the Student's t-test for independent samples and the Mann-Whitney test (total score).

The study observed that there is no significant difference in the individual aspects, in the general classification and in the total score of the modified Lysholm between the sexes, at the level of 5\%.

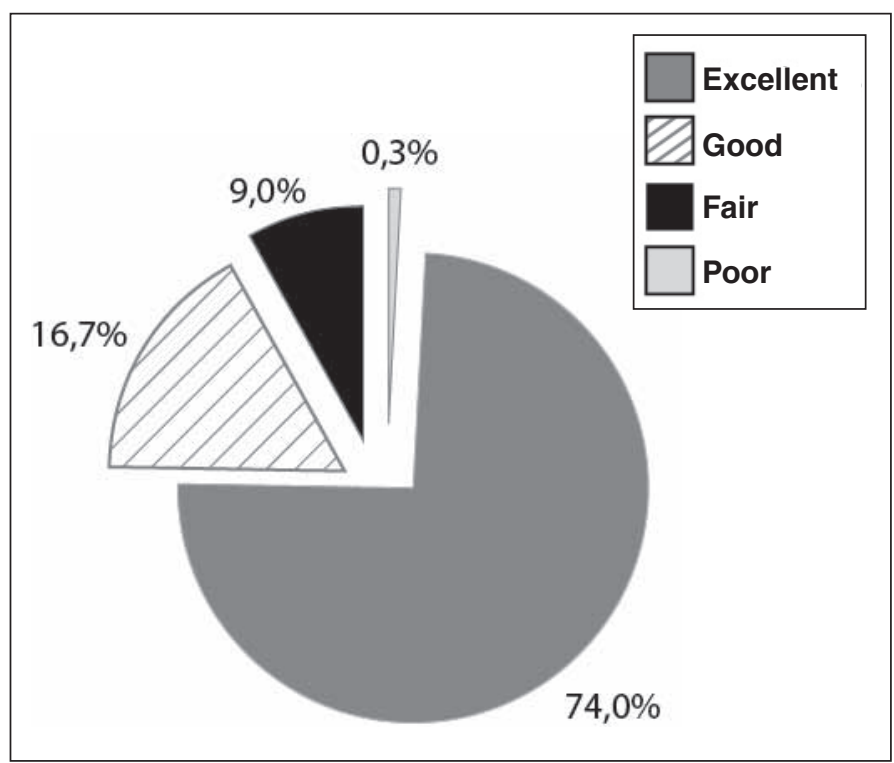

Figure 1 - Distribution of the general classification of the modified Lysholm protocol.

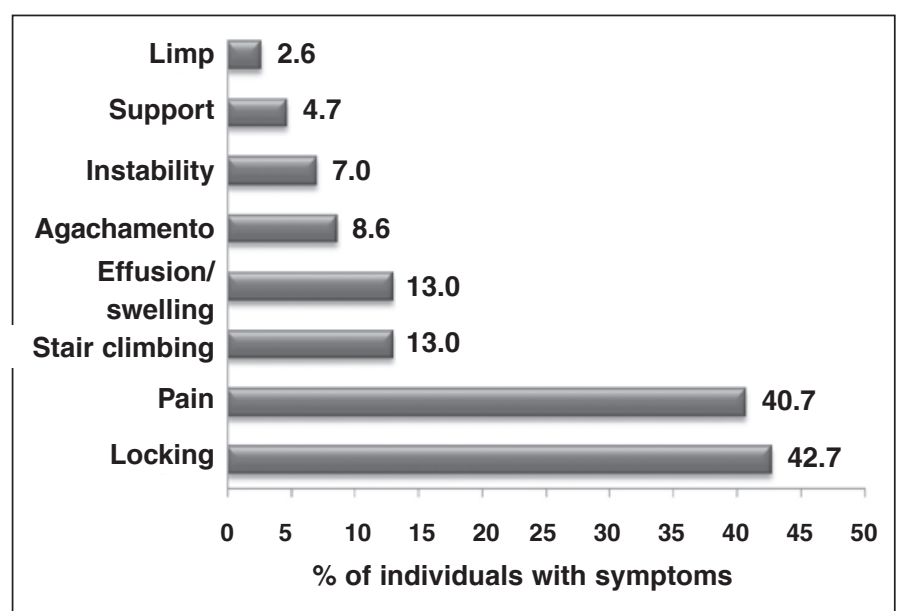

Figure 2 - Decreasing distribution of individuals with some type of symptom related to the aspects of the modified Lysholm protocol (\%).
Table 3 - Analysis of the individual aspects and general classification of the modified Lysholm system according to sex.

\begin{tabular}{|c|c|c|c|c|c|c|}
\hline \multirow{2}{*}{$\begin{array}{l}\text { Modified } \\
\text { Lysholm }\end{array}$} & \multirow{2}{*}{ Category } & \multicolumn{2}{|c|}{$\begin{array}{c}\text { Male } \\
(n=153)\end{array}$} & \multicolumn{2}{|c|}{$\begin{array}{c}\text { Female } \\
(n=147)\end{array}$} & \multirow{2}{*}{$p$ value } \\
\hline & & $\mathbf{n}$ & $\%$ & $\mathbf{n}$ & $\%$ & \\
\hline \multirow{3}{*}{ Limp } & Severe or constant & 0 & 0.0 & 1 & 0.7 & \multirow{3}{*}{0.58} \\
\hline & Slightly & 3 & 2.0 & 4 & 2.7 & \\
\hline & None & 150 & 98.0 & 142 & 96.6 & \\
\hline \multirow{2}{*}{ Support } & Limp & 8 & 5.2 & 6 & 4.1 & \multirow{2}{*}{0.63} \\
\hline & None & 145 & 94.8 & 141 & 95.9 & \\
\hline \multirow{4}{*}{ Squatting } & Impossible & 1 & 0.7 & 0 & 0.0 & \multirow{4}{*}{0.63} \\
\hline & Up to 90 degrees & 0 & 0.0 & 1 & 0.7 & \\
\hline & Slightly impaired & 11 & 7.2 & 13 & 8.8 & \\
\hline & No problem & 141 & 92.2 & 133 & 90.5 & \\
\hline \multirow{2}{*}{ Stair climbing } & Slightly impaired & 18 & 11.8 & 21 & 14.3 & \multirow{2}{*}{0.51} \\
\hline & No problem & 135 & 88.2 & 126 & 85.7 & \\
\hline \multirow{2}{*}{$\begin{array}{l}\text { Joint effusion/ } \\
\text { swelling }\end{array}$} & On severe exertion & 24 & 15.7 & 15 & 10.2 & \multirow[t]{2}{*}{0.15} \\
\hline & None & 129 & 84.3 & 132 & 89.8 & \\
\hline \multirow{3}{*}{ Locking } & Occasional & 6 & 3.9 & 2 & 1.4 & \multirow{3}{*}{0.27} \\
\hline & $\begin{array}{l}\text { "Catching" } \\
\text { sensation }\end{array}$ & 64 & 41.8 & 56 & 38.1 & \\
\hline & None & 83 & 54.3 & 89 & 60.5 & \\
\hline \multirow{4}{*}{ Pain } & $\begin{array}{c}\text { On walking } 2 \mathrm{~km} \text { or } \\
\text { more }\end{array}$ & 3 & 2.0 & 5 & 3.4 & \multirow{4}{*}{0.78} \\
\hline & On severe exertion & 15 & 9.8 & 11 & 7.5 & \\
\hline & $\begin{array}{l}\text { Inconstant } \\
\text { or slight }\end{array}$ & 44 & 28.8 & 44 & 29.9 & \\
\hline & None & 91 & 59.5 & 87 & 59.2 & \\
\hline \multirow{3}{*}{ Instability } & $\begin{array}{l}\text { Occasionally in } \\
\text { daily activities }\end{array}$ & 3 & 2.0 & 2 & 1.4 & \multirow{3}{*}{0.75} \\
\hline & $\begin{array}{l}\text { Rarely during } \\
\text { sports activities }\end{array}$ & 7 & 4.6 & 9 & 6.1 & \\
\hline & $\begin{array}{l}\text { Has never pre- } \\
\text { sented buckling }\end{array}$ & 143 & 93.5 & 136 & 92.5 & \\
\hline \multirow{4}{*}{$\begin{array}{l}\text { General clas- } \\
\text { sification }\end{array}$} & Excellent & 110 & 71.9 & 112 & 76.2 & \multirow{4}{*}{0.41} \\
\hline & Good & 26 & 17.0 & 24 & 16.3 & \\
\hline & Fair & 17 & 11.1 & 10 & 6.8 & \\
\hline & Poor & 0 & 0.0 & 1 & 0.7 & \\
\hline \multirow{2}{*}{$\begin{array}{c}\text { General clas- } \\
\text { sification } \\
\text { (grouped) }\end{array}$} & Excellent & 110 & 71.9 & 112 & 76.2 & \multirow{2}{*}{0.39} \\
\hline & Not excellent & 43 & 28.1 & 35 & 23.8 & \\
\hline Age (years) & $\begin{array}{l}\text { Mean } \pm \text { SD - } \\
\quad \text { Median }\end{array}$ & \multicolumn{2}{|c|}{$\begin{array}{c}29.6 \pm 5.8 \\
-29\end{array}$} & \multicolumn{2}{|c|}{$\begin{array}{c}29.1 \pm 6.4 \\
-28\end{array}$} & $0.47^{b}$ \\
\hline $\begin{array}{l}\text { Total score } \\
\text { (points) }\end{array}$ & $\begin{array}{l}\text { Mean } \pm \text { SD - } \\
\quad \text { Median }\end{array}$ & \multicolumn{2}{|c|}{$\begin{array}{c}92.9 \pm 6.7- \\
95\end{array}$} & \multicolumn{2}{|c|}{$\begin{array}{c}92.4 \pm 7.0 \\
-95\end{array}$} & $0.42^{c}$ \\
\hline
\end{tabular}

${ }^{a} \chi^{2}$ test or Fisher's exact test

${ }^{\mathrm{b}}$ Student's t-test for independent samples.

${ }^{\mathrm{c}}$ Mann-Whitney test. 


\section{DISCUSSION}

There is a vast amount of scientific production relating to surgical procedures on the knee; nevertheless, it is difficult to compare results between different students. When we specifically compare the knee evaluation systems, we observe various studies with results of non-concordance between systems ${ }^{(4-6)}$. However, we can still find some authors today who do not use knee scoring systems to evaluate the clinical follow-up of their patients ${ }^{(7)}$.

We believe that such a difficulty is due to the fact that the available evaluation systems are not completely satisfactory.

The IKDC presents very interesting characteristics, as it aims to perform a subjective, objective and functional assessment ${ }^{(8)}$. Although it initially appears to be a perfect system, we observed some deficiencies in its use. Its final result is represented by the worst result of all the sub-items investigated. Thus the patient's overall evaluation is very radically penalized, often not reflecting their functional level.

Abdalla et $a l^{(9)}$ concluded that the Cincinnati system was superior to the other two studied, namely, Lysholm and IKDC. They compared two groups: one group six months after ACL reconstruction surgery and the other composed of volunteers without previous knee injuries. In the evaluation of the Lysholm and Cincinnati questionnaires, they observed similar results between both groups. The evaluation of the IKDC protocol presented inferior rating results in comparison to the other two questionnaires. Moreover, it rated $46.6 \%$ of the group without previous injury as subnormal and abnormal, corroborating our opinion that the IKDC protocol evidencing a poor result in a subgroup penalizes the final evaluation.

Brinker et $a l^{(10)}$ conducted a study with 91 athletes without previous knee injuries and compared four systems: IKDC, Lysholm, Feagin \& Blake and HSS. The IKDC presented non-concordant results that were of inferior value when compared to the other three protocols, and only $60 \%$ of these athletes without previous knee injuries were rated normal. Our survey is consistent with this affirmation and observes that so-called normal patients do not reach the maximum rating in the Lysholm score.

Sernert et $a l^{(11)}$ evaluated 527 patients submitted to ACL reconstruction with the IKDC protocol. They concluded that the IKDC protocol is valid and useful for evaluating ACL reconstructions. However, when we observed the outcome of the survey, just $33.6 \%$ of the patients were considered with a normal score, evidencing the stringent evaluation criterion of the IKDC. In the middle of the preparation of our study, the IKDC was validated in Brazil; however, due to its stringent final evaluation system, we decided not to use it ${ }^{(12)}$.

McAllister et $a l^{(13)}$ compared elite university athletes with and without ACL injury with the Lysholm and Tegner systems, two subjective items of the IKDC and the SF-36 protocol. There was no statistically significant difference, except for the IKDC. Our opinion is based on the fact that patients with ACL injury present repeated buckling, generating a lower functional assessment score. Consequently, we decided to evaluate only patients with normal knees.

Lysholm and Gillquist ${ }^{(14)}$, when comparing their evaluation system with that of Larson, emphasized its specificity in measuring the functional level more adequately, as it expresses the patient's opinion about their own knee. In the use of this system, they concluded that, besides adequately assessing functional level, it was easy for patients to understand and apply, confirming what we observed in our study on Lysholm's modified protocol.

Tegner and Lysholm ${ }^{(2)}$ assessed 76 patients with ACL injury and compared the modified Lysholm protocol with the Hospital for Special Surgery's first form. Binary questions, requiring answers such as "yes" or "no", provided less detail than the modified Lysholm scale. They concluded that the stability test, performance test, functional score and activity level should not be included in the same scoring scale. They believe that each assessment was important at different times during the treatment of the ligament injury, and that they should therefore be analyzed separately. When we compared this with our study, we observed that the modified Lysholm system appropriately classifies patients without previous knee injury as "excellent", yet we did not verify the maximum score obtained.

Sgaglione et $a l^{(15)}$ compared four knee rating systems: score of the Hospital for Special Surgery, Lysholm, Tegner and Cincinnati. They concluded, in comparing the Lysholm test with other methods, that it is of a subjective nature as regards functional as- 
sessment of the knee, and that when in use it should be associated with another method. They support the use of a protocol with subjective, objective and functional assessment, with individualized rather than general results. We agree with this conclusion, as we believe that a subjective, objective and functional assessment creates a more complete scoring system and a more precise evaluation. We used the modified Lysholm system as it is one of the knee evaluation systems used most often in literature and the only one validated in Brazil when we started our survey.

Höher et $a l^{(16)}$, in their study, assessed 61 patients one year after ACL reconstruction and compared the result of the Lysholm protocol self-administered by the patient compared to that applied by the examiner, and also draw our attention to the fact that the examiner could influence the functional assessment result, since they are usually involved in the survey in question. They confirm our opinion that the knee assessment protocol should be composed of a subjective, objective and functional component to reduce examiner interference. We believe that the examiner should be the one to conduct the survey, as a layman would not know how to distinguish between buckling or locking investigated in the modified Lysholm protocol.

There are scoring systems in which the method of assessment is visual analogue. This method of evaluating subjective findings has proven efficacy ${ }^{(17)}$; however, we observed some difficulties in its application. As it is a scale, the patient's understanding of the test requires notions of mathematics and proportion, skills usually acquired at school. In our group we found a large number of patients with a low level of education, to whom the understanding of the test would require several explanations by the examiner. In these eventualities it was clear how the final score can be influenced by external interferences ${ }^{(16,18)}$, which, in our opinion, is the main disadvantage of this kind of system.

Labs and Paul ${ }^{(5)}$, in a prospective study of 56 patients with ACL reconstruction, compared eight knee rating systems. In analyzing the results of the knee rating systems, they concluded that they are incomparable, since there are individual variations of the subjective, objective and functional parameters. They observed that there is frequently disagreement betwe- en subjective satisfaction and objective results.

As regards sex, we perceived that the functional assessment score of the women was lower than that of the men, probably due to the greater patellofemoral complaint and more accentuated genus valgum.

Aiming to decrease the bias ${ }^{(19)}$, our survey was conducted by only one examiner experienced in the use of this scoring system. On the other hand, Demirdjian et $a l^{(20)}$ carried out a semiological evaluation using some colleague or another with a different degree of experience. We believe that this study loses its credibility and that the likelihood of errors increases. The inclusion criteria used in our survey were: absence of complaints or previous surgery on the knee considered dominant. As regards possible knee symptoms, anything that could limit the functional assessment was considered relevant. We emphasize that crepitation in the patellofemoral joint, or pain at the femorotibial interline, were not exclusion criteria, as in our understanding, they are hardly trustworthy findings for defining a knee as abnormal. In our study, no patient was excluded due to symptoms in the knee. Moreover, we executed a bilateral radiographic evaluation in which we compared the knees for better functional analysis. Complaints of pain, locking and climbing stairs were mentioned the most often, respectively. Previous pain in the knee was the main cause of these findings, since it is the main complaint of the population in general ${ }^{(21)}$. Briggs et $a l^{(22)}$ conclude that even a high level athlete might not achieve the score of excellent, an opinion corroborated by us.

The study suggests that this line of research on knee rating systems is open for new studies. Furthermore, we should investigate the creation and the preparation of new knee assessment forms to obtain a consensus on a better knee assessment scoring system.

\section{CONCLUSION}

The patients with knee considered normal did not obtain the maximum score in the assessment by the modified Lysholm protocol. The study suggests that this line of research on systems for functional knee assessment is open to further evaluation. In addition, we should investigate the creation and the preparation of new functional knee assessment forms to obtain a worldwide consensus. 


\section{REFERENCES}

1. O' Donoghue DH. An analysis of end results of surgical treatment of major injuries to the ligaments of the knee. J Bone Joint Surg Am. 1955;37 A(1):1-13.

2. Tegner $Y$, Lysholm J. Rating systems in the evaluation of knee ligament injuries. Clin Orthop Relat Res. 1985;(198):43-9.

3. Peccin MN, Ciconelli R, Cohen M. Specific questionnaire for knee symptomsThe Lysholm knee scoring scale- Translation and validation into Portuguese. Acta Ortop Bras. 2006;14(5): 268-72.

4. Hrubesch R, Rangger C, Reichkendler M, Sailer RF, Gloetzer W, Eibl G. Comparison of score evaluations and instrumented measurement after anterior cruciate ligament reconstruction. Am J Sports Med. 2000;28(6):850-6.

5. Labs K, Paul B. To compare and contrast the various evaluation scoring systems after anterior cruciate ligament reconstruction. Arch Orthop Trauma Surg. 1997;116(1-2):92-6

6. Bollen S, Seedhom BB. A comparison of the Lysholm and Cincinnati knee scoring questionnaires. Am J Sports Med. 1991;19(2):189-90.

7. Johnson DS, Smith RB. Outcome measurement in the ACL deficient knee-what's the score? Knee. 2001;8(1):51-7.

8. Hefti F, Müller W. [Current state of evaluation of knee ligament lesions. The new IKDC knee evaluation form ]. Orthopade. 1993;22(6):351-62.

9. Abdalla RJ, Camanho GL, Cohen M, Forgas CR, Monteiro CG, Jeremias SL, Mosconi FV. Estudo comparativo entre os questionários de avaliação funcional do joelho: IKDC, Cincinnati e Lysholm. Rev Joelho. 2001;1(1): 11-4.

10. Brinker MR, Garcia R, Barrack RL, Timon S, Guinn S, Fong B. An analysis of sports knee evaluation instruments. Am J Knee Surg. 1999 Winter;12(1):15-24.

11. Sernert N, Kartus J, Köhler K, Stener S, Larsson J, Eriksson BI, Karlsson J. Analysis of subjective, objective and functional examination tests after anterior cruciate ligament reconstruction. A follow-up of 527 patients. Knee Surg Sports Traumatol Arthrosc. 1999;7(3):160-5.
12. Metsavaht L, Leporace G, Riberto M, de Mello Sposito MM, Batista LA. Translation and cross-cultural adaptation of the Brazilian version of the International Knee Documentation Committee Subjective Knee Form: validity and reproducibility. Am J Sports Med. 2010;38(9):1894-9.

13. McAllister DR, Tsai AM, Dragoo JL, McWilliams J, Dorey FJ, Hame SL, et al. Knee function after anterior cruciate ligament injury in elite collegiate athletes. Am J Sports Med. 2003;31(4):560-3.

14. Lysholm J, Gillquist J. Evaluation of knee ligament surgery results with special emphasis on use of a scoring scale. Am J Sports Med. 1982;10(3):150-4.

15. Sgaglione NA, Del Pizzo W, Fox JM, Friedman MJ. Critical analysis of knee ligament rating systems. Am J Sports Med. 1995;23(6):660-7.

16. Höher J, Bach T, Münster A, Bouillon B, Tiling T. Does the mode of data collection change results in a subjective knee score? Self-administration versus interview. Am J Sports Med. 1997;25(5):642-7.

17. Flandry F, Hunt JP, Terry GC, Hughston JC. Analysis of subjective knee complaints using visual analog scales. Am J Sports Med. 1991;19(2):112-8.

18. Roos EM. Outcome after anterior cruciate ligament reconstruction-a comparison of patients' and surgeons' assessments. Scand J Med Sci Sports. 2001;11(5):287-91.

19. Galli M, De Santis V, Tafuro L. Reliability of the Ahlbäck classification of knee osteoarthritis. Osteoarthritis Cartilage. 2003;11(8):580-4.

20. Demirdjian AM, Petrie SG, Guanche CA, Thomas KA. The outcomes of two knee scoring questionnaires in a normal population. Am J Sports Med. 1998;26(1):46-51.

21. Lubowitz JH, Bernardini BJ, Reid JB 3rd. Current concepts review: comprehensive physical examination for instability of the knee. Am J Sports Med. 2008;36(3):577-94.

22. Briggs KK, Steadman JR, Hay CJ, Hines SL. Lysholm score and Tegner activity level in individuals with normal knees. Am J Sports Med. 2009;37(5):898-901. 